\title{
Prevalence of Helicobacter pylori in children in eastern Turkey and molecular typing of isolates
}

\author{
Gokben Ozbey ${ }^{1}$, Yasar Dogan ${ }^{2}$, Kaan Demiroren ${ }^{2}$, Ibrahim Hanifi Ozercan ${ }^{3}$ \\ ${ }^{1}$ Vocational School of Health Services, Firat University, Elazig, Turkey. \\ ${ }^{2}$ Department of Pediatric Gastroenterology, Faculty of Medicine, Firat University, Elazig, Turkey. \\ ${ }^{3}$ Department of Pathology, Faculty of Medicine, Firat University, Elazig, Turkey.
}

Submitted: June 18, 2013; Approved: September 30, 2014.

\begin{abstract}
The objectives of the present study were to determine Helicobacter pylori via culture, polymerase chain reaction and histopathological diagnosis in 101 children ranging in age from 4 to 18 years, to identify the association among restriction fragment length polymorphism types and clinical disease and to investigate the relationships among different isolates of $H$. pylori in different age groups. We observed a high prevalence of $H$. pylori infections in children between the ages of 13 and $18(75.8 \%)$, while children aged 4 to 6 years had the lowest prevalence of infection (40\%). H. pylori was detected in $30.7 \%$ (31 of 101), 66.3\% (67 of 101) and 63.2\% (60 of 95) of children as determined by culture methods, PCR and histological examination, respectively. H. pylori isolates with RFLP types I and III were the most common among children with antral nodularity, whereas RFLP types II and IV were the least detected types. Interestingly, all isolates from peptic ulcer patients were type III. Although our results show a high prevalence of $H$. pylori infections in the pediatric population in eastern Turkey, no association was identified between $H$. pylori infection with antral nodularity and recurring abdominal pain. In addition, we found low genetic variation among $H$. pylori isolates from children and no association between RFLP types and antral nodularity $(\mathrm{p}>0.05)$. Additionally, we found that $H$. pylori isolates with specific RFLP types were predominant in different age groups.
\end{abstract}

Key words: children, culture, Helicobacter pylori, PCR-RFLP.

\section{Introduction}

Most Helicobacter pylori infections are thought to be acquired in childhood or adolescence, and infection with this bacterium at a young age increases the risk of associated complications later in life (Vinette et al., 2004).

Culture methods have been the "gold standard" for the detection of bacterial pathogens, yet for bacteria such as H. pylori, this technique is often difficult and time-consuming (Singh et al., 2008). Serological tests also have limitations such as low specificity and failure to differentiate between active and past infections (Hestvik et al., 2010). Polymerase chain reaction (PCR)-based techniques have successfully been used to detect pathogens that may be difficult to culture, identify and/or isolate from clinical samples (Singh et al., 2008). PCR-based restriction fragment length polymorphism (RFLP) analysis, used in this study, has sufficient discriminatory power to differentiate among H. pylori strains, in addition to being a relatively simple, fast and low cost sub-typing method (Andreson et al., 2007; Li et al., 1997).

Currently, little is reported about the prevalence of active H.pylori infections among children in the Elazig Province of eastern Turkey. The aims of this study were to: (i) identify the prevalence of active H.pylori infection among children and determine if prevalence differs with age, (ii) evaluate any correlation between $H$. pylori infection and gastroduodenal disease and (iii) determine if $H$. pylori RFLP sub-types are associated with antral nodularity, peptic ulcer, specific age groups and/or clinical outcomes. 


\section{Materials and Methods}

\section{Patients}

A total of 101 patients were enrolled in this study, including 53 girls and 48 boys ages 4 to 18 years (Ozbey et al., 2013). Symptoms included recurrent abdominal pain, vomiting with or without blood, bloody stools and growth retardation. The children underwent endoscopy at the clinic of Pediatric Gastroenterology Department at the Firat University Hospital in the period of March 2011 to September 2012 (Ozbey et al., 2013) Ethical clearance for this study was provided by the Medical Ethics Committee of Firat University. Informed consent was obtained from each patient and signed by the children's parents prior to the endoscopy procedure.

\section{Bacterial culture}

Bacterial culturing of the antral biopsy was performed as described elsewhere (Chomvarin et al., 2006). Briefly, the antral biopsies were placed directly into sterile Eppendorf tubes containing $0.5 \mathrm{~mL}$ of Brain Heart Infusion broth (Oxoid, Basingstoke, UK) with $15 \%$ glycerol and processed for culture within $2 \mathrm{~h}$. Each sample was smeared onto Columbia agar base (Oxoid, UK) added with 7\% laked horse blood (SR0048C, Oxoid, UK) and H. pylori Dent's supplement (Oxoid, UK). Plates were incubated at $37^{\circ} \mathrm{C}$ in a microaerobic atmosphere using the Campygen gas generating kit (Oxoid, UK) for up to 10 days (Frenck et al., 2006). Typical small, round colonies that were gram negative and urease, catalase and oxidase positive were presumed to be H. pylori (Goodwin and Wesley, 1993). All isolates were stored at $-80^{\circ} \mathrm{C}$ in Brain Heart Infusion broth added with $15 \%$ glycerol until further analysis. Reference H. pylori strains, including some clinical strains, were provided by the Department of Medical Biology, Faculty of Medicine, Pamukkale University, Denizli, Turkey. The histological evaluation of each antral biopsy sample was conducted by a pathologist according to the Sydney classification system (Dixon et al., 1996).

\section{Primers and PCR conditions}

DNA from antral biopsy samples and suspensions of H. pylori colonies were purified using the QIAamp DNA mini kit (Qiagen, Germany). The forward [ $g \operatorname{lm} \mathrm{M}-\mathrm{F}$ (5'-AAGCTTTTAGGGGTGTTAGGGGTTT-3')] and reverse [ $g l m \mathrm{M}-\mathrm{R}$ (5'-AAGCTTACTTTCTAACACTAAC GC-3')] primers (Lu et al., 1999) amplify a region of the glm M gene (formerly ureC) of $H$. pylori to yield a $294 \mathrm{bp}$ PCR product. The thermal cycling was as follows: $35 \mathrm{cy}-$ cles of denaturation at $93{ }^{\circ} \mathrm{C}$ for $1 \mathrm{~min}, 1 \mathrm{~min}$ at an annealing temperature of $55^{\circ} \mathrm{C}$, and a 1 min extension step at $72{ }^{\circ} \mathrm{C}$ (Lu et al., 1999).

\section{PCR-based amplification and RFLP analysis of PCR amplicons}

For PCR-RFLP analysis, the ureC gene was amplified using the forward ureC-U (5'- AAG AAG TCA AAA ACG CCC CAA AAC -3') and reverse ureC-L (5'- CTT ATC CCC ATG CAC GAT ATT CCC -3 ') primers to yield a PCR product size of 1169 bp (Li et al., 1997). The PCR cycling consisted of the following steps: a denaturation step at $94{ }^{\circ} \mathrm{C}$ for $5 \mathrm{~min}, 45$ cycles at $94{ }^{\circ} \mathrm{C}$ for $45 \mathrm{~s}, 59^{\circ} \mathrm{C}$ for $30 \mathrm{~s}$, $72{ }^{\circ} \mathrm{C}$ for $1 \mathrm{~min} 30 \mathrm{~s}$, and a final extension step at $72{ }^{\circ} \mathrm{C}$ for 10 min (Andreson et al., 2007). Ten microliters of PCR product was restricted with the restriction enzyme HhaI (Fermentas, Lithuania) according to the manufacturer's instructions.

\section{Statistical analysis}

Statistical analysis was performed using the statistical software program SPSS 12.00 (SPSS, Chicago, IL, USA). Relationships among the prevalence of $H$. pylori in children and the RFLP types with clinical outcomes were analyzed using Fisher's exact and Pearson's $\chi^{2}$ tests. A $p$ value $<$ 0.05 is statistically significant.

\section{Results}

Of the 101 patients analyzed, 58 (57.4\%) were experiencing abdominal pain, $22(21.8 \%)$ had growth retardation, $12(11.9 \%)$ had bloody vomit and/or blood in stools, 8 (7.9\%) were vomiting, and $1(1 \%)$ was diagnosed with anemia. Endoscopic findings revealed antral nodularity, antral hyperemia, hyperemia in duodenal mucosa, duodenal ulcers and gastric ulcers in $54.5 \%, 12.9 \%, 23.8 \%, 3 \%$ and $5.9 \%$ of cases, respectively.

\section{Culture and PCR results}

Helicobacter pylori was detected in antral gastric biopsies by culture, PCR and histology in 30.7\%, 66.3\% and $63.2 \%$ of patients, respectively (Table 1 ). All H. pylori isolates examined generated the expected $294 \mathrm{bp}$ fragment of the $g \operatorname{lm} \mathrm{M}$ gene (Figure 1). Patients 13 to 18 years of age showed the highest prevalence of infection $(75.8 \%)$, while children 4 to 6 years of age had the lowest prevalence $(40 \%)$ (Table 2). There was no statistically significant difference in the prevalence of $H$. pylori between males $(66.7 \%, 32 / 48)$ and females $(67.9 \%, 36 / 53)$. H. pylori was detected by PCR in $76.4 \%$ (42/55) of cases presenting with

Table 1 - Prevalence of H. pylori as determined by culture, PCR and histopathological findings.

\begin{tabular}{lccc}
\hline Tests & H. pylori $(+) \mathrm{n}(\%)$ & H. pylori $(-) \mathrm{n}(\%)$ & Total (n) \\
\hline culture & $31(30.7)$ & $70(69.3)$ & 101 \\
PCR & $67(66.3)$ & $34(33.7)$ & 101 \\
Histopathology & $60(63.2)$ & $35(36.8)$ & 95 \\
\hline
\end{tabular}




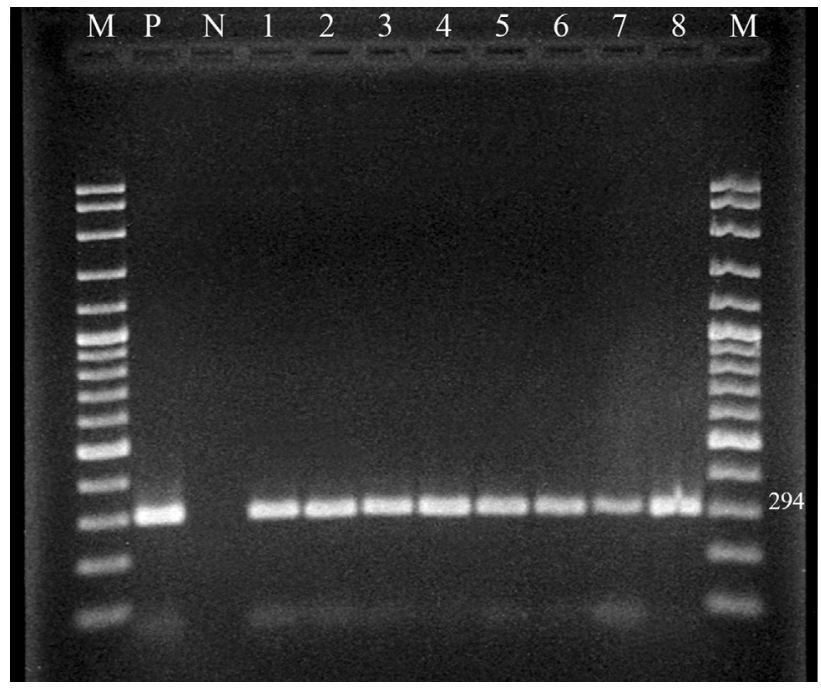

Figure 1 - An agarose gel of PCR products of $H$. pylori isolates from antral biopsy specimens (M: DNA Ladder (100 bp), P: H. pylori positive control, $\mathrm{N}$ : negative control, 1-8: H. pylori positive samples).

antral nodularity, $46.2 \%(6 / 13)$ presenting with antral hyperemia, $50 \%(12 / 24)$ presenting with hyperemia in duodenal mucosa, $66.7 \%(2 / 3)$ presenting with duodenal ulcers and $83.3 \%(5 / 6)$ presenting with gastric ulcers (Table 3). Statistical analysis was not performed because the number of cases for a particular symptom or diagnosis was relatively small. However, the number of cases of recurring abdominal pain and antral nodularity were relatively high. $H$. pylori was detected in $68.9 \%(40 / 58)$ of cases reporting recurring abdominal pain, but no correlation was found between the prevalence of $H$. pylori infection with recurring abdominal pain and that with antral nodularity.

Table 2 - H. pylori prevalence according to different age groups.

\begin{tabular}{lccc}
\hline Years & H. pylori $(+) \mathrm{n}(\%)$ & H. pylori $(-) \mathrm{n}(\%)$ & Total $(\mathrm{n})$ \\
\hline $4-6$ & $2(40)$ & $3(60)$ & 5 \\
$7-12$ & $40(63.5)$ & $23(36.5)$ & 63 \\
$13-18$ & $25(75.8)$ & $8(24.2)$ & 33 \\
\hline
\end{tabular}

Table 3 - Prevalence of $H$. pylori isolates in children according to endoscopic findings as detected by PCR.

\begin{tabular}{lcc}
\hline Endoscopic findings & H. pylori $(+) \mathrm{n}(\%)$ & H. pylori $(-) \mathrm{n}(\%)$ \\
\hline Antral nodularity $(\mathrm{n}=55)$ & $42(76.4)$ & $13(23.6)$ \\
Antral hyperemia $(\mathrm{n}=13)$ & $6(46.2)$ & $7(53.8)$ \\
$\begin{array}{l}\text { Hyperemia in duodenal } \\
\text { mucosa }(\mathrm{n}=24)\end{array}$ & $12(50)$ & $12(50)$ \\
Duodenal ulcer $(\mathrm{n}=3)$ & $2(66.7)$ & $1(33.3)$ \\
Gastric ulcer $(\mathrm{n}=6)$ & $5(83.3)$ & $1(16.7)$ \\
Total $(101)$ & $67(66.3)$ & $34(33.7)$ \\
\hline
\end{tabular}

n: number of $H$. pylori isolates.

\section{Histopathology results}

Six cases were excluded because of insufficient tissue for histopathological examination. Of the remaining 95 antrum biopsy samples, histological examination showed that $60(63.2 \%)$ were positive for H. pylori. Pathological analysis of the biopsy material showed that intestinal metaplasia was present in only a single child (a 13-year old male) who also had chronic gastritis and was H. pylori positive. None of the cases presented with gastric atrophy.

\section{RFLP analysis results}

PCR amplification of $H$. pylori DNA using the ureC primer set produced an amplicon of the expected size (1169 bp) for all H. pylori isolates examined. The RFLP analysis of our isolates revealed a low heterogeneity among isolates. Table 4 shows the distribution of $H$. pylori RFLP types. Four profiles (types I, II, III and IV) were identified (Figure 2). From the cases with antral nodularity, types I $(44.8 \%)$ and III $(27.6 \%)$ were the predominant strains while types II and IV were detected at in lower numbers ( $10.4 \%$ and $17.2 \%$, respectively). From cases presenting with peptic ulcers, only type III $H$. pylori was detected.

Only two isolates from culture were obtained from the 4 to 6 year old age group; one was RFLP type I and the other type II. In the 7 to 12 year old age group (17 isolates positive by culture), $47 \%$ of isolates were type I $(8 / 17)$, $5.9 \%$ type II (1/17), 35.3\% type III (6/17) and $11.8 \%$ type IV (2/17). In addition, both types I and III were detected in $33.3 \%(4 / 12)$ of 13 to 18 year olds. Likewise, types II and IV were detected in the same percentage of children $(16.7 \%, 2 / 12)$ within this age group (Table 5). However, due to the relatively small number of children with peptic ulcers, the statistical analysis required to associate RFLP types with this medical condition could not be performed. No relationship was identified between RFLP type and antral nodularity in the present work $(\mathrm{p}>0.05)$.

\section{Discussion}

Acquiring knowledge on H. pylori infections is important for human pathogen studies because the lack of current knowledge is hindering actions to protect human health. Although RFLP analysis of $H$. pylori isolates in

Table 4 - RFLP types of 31 clinical H. pylori isolates obtained after digestion with HhaI enzyme.

\begin{tabular}{lccc} 
RFLP types & Antral nodularity n (\%) & Peptic ulcer n (\%) & Total n (\%) \\
\hline I & $13(44.8)$ & - & $13(41.9)$ \\
II & $3(10.4)$ & - & $3(9.7)$ \\
III & $8(27.6)$ & $2(100)$ & $10(32.3)$ \\
IV & $5(17.2)$ & - & $5(16.1)$ \\
Total & 29 & 2 & 31 \\
\hline
\end{tabular}

n: number of $H$. pylori isolates. 


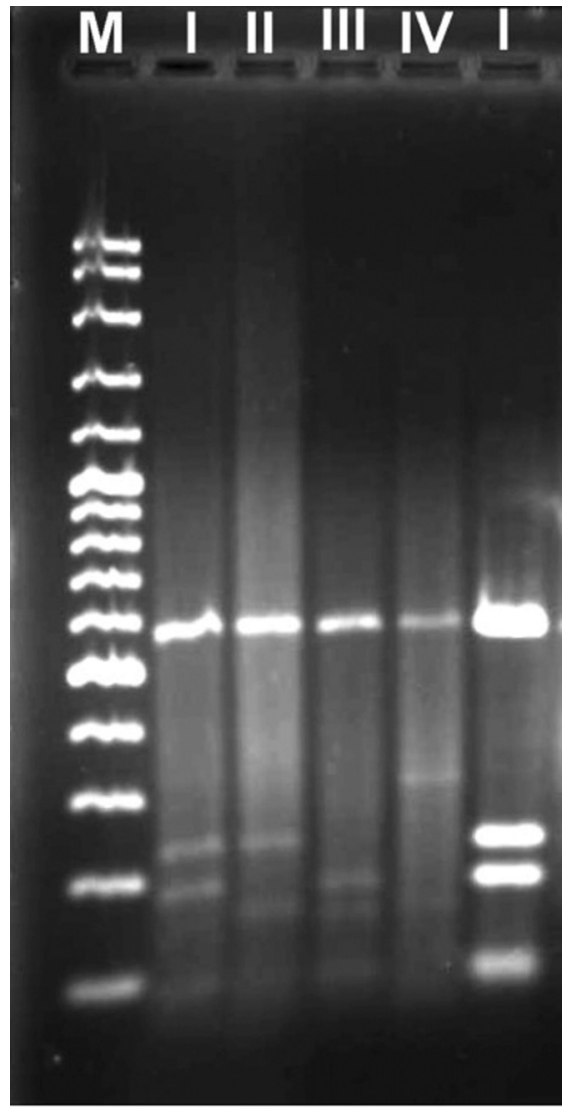

Figure 2 - PCR-RFLP analysis of $H$. pylori isolates using restriction enzymes in agarose gel $(2.5 \% \mathrm{w} / \mathrm{v})$ (M: $100 \mathrm{bp}$ DNA ladder, lanes I, II, III and IV: RFLP band profiles).

Table 5 - RFLP types of $31 \mathrm{H}$. pylori isolates determined after culturing and grouped according to patient age.

\begin{tabular}{lccc}
\hline RFLP types & $4-6 \mathrm{n}(\%)$ & $7-12 \mathrm{n}(\%)$ & $13-18 \mathrm{n}(\%)$ \\
\hline I & $1(50)$ & $8(47)$ & $4(33.3)$ \\
II & - & $1(5.9)$ & $2(16.7)$ \\
III & - & $6(35.3)$ & $4(33.3)$ \\
IV & $1(50)$ & $2(11.8)$ & $2(16.7)$ \\
Total & 2 & 17 & 12 \\
\hline
\end{tabular}

n: number of $H$. pylori isolates.

adults has been performed in eastern Turkey (Ozbey et al., 2012), there are currently no studies that report the isolation and genotyping of $H$. pylori in children residing in this same region. The current study was undertaken to examine the prevalence and genetic diversity of $H$. pylori isolates from children in the Elazig Province of Turkey. These results suggest that appropriate and effective treatment strategies should be implemented against $H$. pylori infections in the future.

The majority of studies investigating the prevalence of $H$. pylori among children in Turkey have employed serological methods (Selimoglu et al., 2002; Yucel et al., 2009). Other studies show varied prevalence of $H$. pylori in asymptomatic children including $7.1 \%$ in the Czech Republic (0-15 year olds), $24.7 \%$ in Israel (0-5 year olds), $30.9 \%$ in Turkey (2-12 year olds), $31.6 \%$ in Portugal ( $0-15$ year olds) and 82\% in Iran (0-15 year olds) (Alborzi et al., 2006; Kori et al., 2009; Oleastro et al., 2011; Sykora et al., 2009; Yucel et al., 2009). We found that the highest prevalence of infection was found in children from 13 to 18 years of age ( $75.8 \%)$. Our study also showed that a total of $66.3 \%$ of symptomatic children were infected with $H$. pylori as detected by PCR. A lower prevalence of $H$. pylori in children with dyspepsia (38\%) was reported in the United States (Sood et al., 2005). However, our findings match previous data reported by Selimoglu et al. (2002) in randomly selected healthy children between the ages of 6 and 17 in Turkey (64.4\% infected). This higher $H$. pylori prevalence may be due to sociodemographic factors such as low socioeconomic status, poor sanitary conditions, higher percentage of low-income families, higher percentage of parents with a low educational background, poor living conditions, high density living quarters and higher rates of immigrant children from the surrounding cities (Azevedo et al., 2009).

Culture-positive biopsies were relatively low at $30.7 \%(31 / 101)$ as compared to histological and PCR results but were similar to the number of positive biopsies detected in Turkey's neighbor, Iran, which reported a $H$. pylori prevalence of $39.8 \%$ using the culture method (Iranikhah et al., 2013). Negative culture results may be due to low colonization because of patchy localization of bacteria in the stomach, decreased bacterial viability, overgrowth of potential contaminants, technical problems during tissue transport, increased transportation times and varied culturing methods (Ozcay et al., 2004; Torres et al., 2001).

In this study, most of the children reported recurrent abdominal pain, but the role of $H$. pylori in causing chronic abdominal pain is still disputable (Zeyrek et al., 2008; Hestvik et al., 2010). Our data showed no significant correlation between abdominal symptoms and $H$. pylori infection.

Bahu et al. (2003) noted a significant relationship between $H$. pylori and endoscopic nodular gastritis. Here, antral nodularity was observed in 55 children $(54.5 \%$ of those tested) of which $76.4 \%$ were positive for $H$. pylori. This observation is similar to previous data $(73.8 \%)$ reported by Dogan et al. (2007) but higher than that reported in Turkey (64.7\%) by Ozcay et al. (2004) and lower than reported in Japan where $98.5 \%$ of $H$. pylori cases were associated with antral nodularity (Kato et al., 2004).

Reports show that the peptic ulcer prevalence in children in different countries varies between $1.8 \%$ to $19.5 \%$ (Elitsur and Lawrence, 2001; Kato et al., 2004). In the present study, $8.9 \%$ of symptomatic children had peptic ulcers, similar to results reported by Megraud (2005) in European children (8.6\%) but lower than those reported by Ugras and Pehlivanoglu (2011) in Turkish children (13.2\%). However, in the current study, the prevalence of $H$. pylori in pa- 
tients also presenting with ulcers was $66.7 \%$ for those with duodenal ulcers and $83.3 \%$ for those with gastric ulcers. The percentage for those with duodenal ulcers is lower than the earlier reports from Japan and Turkey where $83 \%$ and $76.9 \%$, respectively, of patients with duodenal ulcers were positive for H. pylori (Kato et al., 2004; Ugras and Pehlivanoglu, 2011). In this study, a similar number of children with gastric ulcers tested positive for $H$. pylori $(83.3 \%)$, as was reported $(85.2 \%)$ previously in Turkey (Ugras and Pehlivanoglu, 2011).

In areas with high incidence rates of gastric cancer, gastric atrophy is common among H.pylori-infected children (Ricuarte et al., 2005). The prevalence of gastric atrophy varies between countries, and it has been shown that intestinal metaplasia alters with respect to geographic/genetic origins and environmental factors (Kato et al., 2006: Pacifico et al., 2010; Ricuarte et al., 2005; Tutar et al., 2009; Usta et al., 2004). Only one of the 95 symptomatic children $(1.1 \%)$ had intestinal metaplasia and was positive for $H$. pylori. These data are in concordance with a previous report(Usta et al., 2004) that found intestinal metaplasia in only one of 175 Turkish children infected with $H$. pylori. However, only $4.6 \%$ of children in Japan with intestinal metaplasia were positive for $H$. pylori (Kato et al. 2006). In contrast, the prevalence of gastric atrophy is high in Columbian children (16\%) and much higher in Japanese children (51.9\%) (Kato et al., 2006; Ricuarte et al., 2005).

PCR-RFLP has been frequently used for genotyping and discrimination of $H$. pylori strains because it is low cost, rapid, easy to perform and can be used to analyze $H$. pylori genotype diversity (Röesler et al., 2009). The two re-

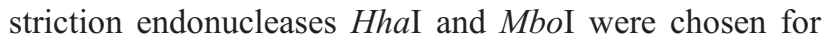
RFLP analysis of the ureC gene (Li et al., 1997). RFLP analysis of the PCR products of our $H$. pylori isolates yielded four different RFLP types (I, II, III and IV). RFLP types I and III were the most frequently detected among children with antral nodularity whereas RFLP types II and IV were detected less frequently. Furthermore, type III was the most predominant type in isolates from patients with peptic ulcers. Our findings confirmed the results of Mishra et al. (2002), Saribasak et al. (2004) and Kulsantiwong et al. (2012) who reported no correlation between the RFLP patterns of all strains and the patients' clinical outcome. In addition, certain RFLP profiles predominated according to different age groups; types I and IV (50\%) in 4-6 year olds, type I ( $47 \%)$ in $7-12$ year olds and types I and III (33.3\%) in 13-18 year olds. These percentages show that children within different age groups were infected with various $H$. pylori strains, which might be related to differences in immune responses towards $H$. pylori during childhood development. Further study is needed to better establish this relationship.

High genetic variation in $H$. pylori strains isolated from various patients has been demonstrated worldwide (Raymond et al., 2005; Kulsantiwong et al., 2012; Menoni et al., 2013). This result is in contrast to the current study where $H$. pylori isolates from children showed a considerably low genetic diversity. However, limited PCR-RFLP profiles might be due to the small numbers of $H$. pylori isolates in the present study (31 total isolates).

In conclusion, the results of the current study show a high prevalence of $H$. pylori infection in children in eastern Turkey. Although the number of H. pylori isolates is too small to perform any epidemiological analysis, the bacterial isolates from children in the present study yielded a relatively small number of genetically distinct RFLP types. A different distribution of RFLP types was evident among children of different age groups. Therefore, it is necessary to conduct future work on larger populations of children in order to fully confirm the results of this study and to identify the genetic heterogeneity of $H$. pylori isolates in children from the Elazig Province.

\section{Acknowledgments}

The abstract form of this study was presented as poster in 1st International Organic Electronic Material Technologies Conference (OEMT 2015), March 25-28, 2015, Elazig, Turkey. The authors thank Dr. Vildan Caner, Department of Medical Biology, Faculty of Medicine, Pamukkale University, Denizli, Turkey, for kindly providing some clinical strains and the management of the Elazig Veterinary Control and Research Institute for securing laboratory facilities for this study. We are also grateful to Dr. Francis Megraud, INSERM U853, Laboratoire de Bacteriologie - C.H.U. Pellegrin, France; Dr. Alfizah Hanafiah, Department of Medical Microbiology and Immunology, Faculty of Medicine, UKM Medical Centre, Kuala Lumpur, Malaysia and Dr. Emma Sproston, Bureau of Microbial Hazards, Health Canada, Ottawa, Canada for critical review of the manuscript.

\section{References}

Alborzi A, Soltani J, Pourabbas B et al. (2006) Prevalence of Helicobacter pylori infection in children (south of Iran). Diagn Microbiol Infect Dis 54:259-261.

Andreson H, Sillakivi T, Peetsalu M et al. (2007) Persistence of Helicobacter pylori infection in patients with peptic ulcer perforation. Scand J Gastroenterol 42:324-329.

Azevedo NF, Huntington J, Goodman KJ (2009) The epidemiology of Helicobacter pylori and public health implications. Helicobacter 14:1-7.

Bahú MG, Silveira TR, Maguilnick I et al. (2003) Endoscopic nodular gastritis: an endoscopic indicator of high-grade bacterial colonization and severe gastritis in children with Helicobacter pylori. J Pediatr Gastroenterol Nutr 36:217222.

Chomvarin C, Kulsantiwong P, Chantarasuk Y et al. (2006) Comparison of media and antibiotic supplements for isolation of Helicobacter pylori from gastric biopsies. Southeast Asian J Trop Med Public Health 37:1163-1169. 
Dixon MF, Genta RM, Yardely JH et al. (1996) Classification and grading of gastritis. The Updated Sydney System. Am J Surg Pathol 20:1161-1181.

Dogan Y, Baris S, Erkan T et al. (2007) Helicobacter pylori infection in children: Evaluation of complaints, endoscopic findings, diagnostic methods and post-treatment eradication rates. Turk Arch Ped 42:98-102.

Elitsur Y, Lawrence Z (2001) Non-Helicobacter pylori related duodenal ulcer disease in children. Helicobacter 6:239-243.

Frenck RW Jr, Fathy HM, Sherif M et al. (2006) Sensitivity and specificity of various tests for the diagnosis of Helicobacter pylori in Egyptian children. Pediatrics 118:e1195-1202.

Goodwin CS, Wesley BW (1993) Microbiology of Helicobacter pylori. Gastroenterol Clin North Am 22:5-19.

Hestvik E, Tylleskar T, Kaddu-Mulindwa DH et al. (2010) Helicobacter pylori in apparently healthy children aged 0-12 years in urban Kampala, Uganda: a community-based cross sectional survey. BMC Gastroenterol 10:62.

Iranikhah A, Ghadir M-R, Sarkeshikian S et al. (2013) Stool antigen tests for the detection of Helicobacter pylori in children. Iran J Pediatr 23:138-142.

Kato S, Nishino Y, Ozawa K et al. (2004) The prevalence of Helicobacter pylori in Japanese children with gastritis or peptic ulcer disease. J Gastroenterol 39:734-738.

Kato S, Nakajima S, Nishino Y et al. (2006). Association between gastric atrophy and Helicobacter pylori infection in Japanese children: a retrospective multicenter study. Dig Dis Sci 51:99-104

Kori M, Goldstein E, Granot E (2009) Helicobacter pylori infection in young children detected by a monoclonal stool antigen immunoassay. Pediatr Infect Dis J 28:157-159.

Kulsantiwong P, Chomvarin C, Mairiang P et al. (2012) PCRRFLP and Antimicrobial susceptibility profilrs of Helicobacter pylori isolated from antrum and corpus in dyspeptic patients in Thailand. Southeast Asian J Trop Med Public Health 43:933-942.

Li C, Ha T, Chi DS et al. (1997) Differentiation of Helicobacter pylori strains directly from gastric biopsy specimens by PCR-based restriction fragment length polymorphism analysis without culture. J Clin Microbiol 35:3021-3025.

Lu JJ, Perng CL, Shyu RY et al. (1999) Comparison of five PCR methods for detection of Helicobacter pylori DNA in gastric tissues. J Clin Microbiol 37:772-774.

Megraud F (2005) On behalf of the European pediatric task force on Helicobacter pylori comparison of non-invasive tests to detect Helicobacter pylori infection in children and adolescents results of a multicenter European study. J Pediatr 146:198-203.

Menoni SMF, Bonon SHA, Zeitune JMR et al. (2013) PCR-based detection and genotyping of Helicobacter pylori in endoscopic biopsy samples from Brazilian patients. Gastroenterol Res Pract 2013:1-8.

Mishra KK, Srivastava S, Prabhat P et al. (2002) PCR-based RFLP analysis of ureC gene for typing of Indian Helicobacter pylori strains from gastric biopsy specimens and culture. J Microbiol 40:282-288.

Oleastro M, Cabral J, Ramalho PM et al. (2011) Primary antibiotic resistance of Helicobacter pylori strains isolated from Portuguese children: a prospective multicentre study over a 10 year period. J Antimicrob Chemother 66:2308-2311.
Ozbey G, Bahcecioglu IH, Ceribasi S et al. (2012) Polymerase chain reaction-restriction fragment length polymorphism analysis of Helicobacter pylori isolates from patients with gastrointestinal complaints in Eastern Turkey. Afr J Microbiol Res 6:4068-4072.

Ozbey G, Dogan Y, Demiroren K (2013) Prevalence of Helicobacter pylori virulence genotypes among children in Eastern Turkey. World J Gastroenterol 19:6585-6589.

Ozcay F, Kocak N, Saltik IN et al. (2004) Helicobacter pylori infection in Turkish children: comparison of diagnostic tests, evaluation of eradication rate, and changes in symptoms after eradication. Helicobacter 9:242-248.

Pacifico L, Anania C, Osborn JF et al. (2010) Consequences of Helicobacter pylori infection in children. World $\mathrm{J}$ Gastroenterol 16:5181-5194.

Raymond J, Nguyen B, Bergeret M et al. (2005). Heterogeneous susceptibility to metronidazole and clarithromycin of Helicobacter pylori isolates from a single biopsy in adults is confirmed in children. Int J Antimicrob Agents 26:272-278.

Ricuarte O, Gutierrez O, Cardona H et al. (2005) Atrophic gastritis in young children and adolescents. J Clin Pathol 58:1189-1193.

Röesler BM, de Oliveira TB, Bonon SH et al. (2009). Restriction fragment length polymorphism of urease $\mathrm{C}$ and urease $\mathrm{B}$ genes of Helicobacter pylori strains isolated from Brazilian patients with peptic ulcer and chronic gastritis. Dig Dis Sci 54:1487-93.

Saribasak H, Salih BA, Yamaoka Y et al. (2004) Analysis of Helicobacter pylori genotypes and correlation with clinical outcome in Turkey. J Clin Microbiol 42:1648-1651.

Selimoglu MA, Ertekin V, Inandi T (2002) Seroepidemiology of Helicobacter pylori infection in children living in eastern Turkey. Pediatr Int 44:666-669.

Singh V, Mishra S, Rao GRK et al. (2008) Evaluation of Nested PCR in detection of Helicobacter pylori targeting a highly conserved gene: HSP60. Helicobacter 13:30-34.

Sood MR, Joshi S, Akobeng AK et al. (2005) Growth in children with Helicobacter pylori infection and dyspepsia. Arch Dis Child 90:1025-1028.

Sykora J, Siala K, Varvarovska J et al. (2009) Epidemiology of Helicobacter pylori infection in asymptomatic children: a prospective population-based study from the Czech Republic. Application of a monoclonal-based antigen in-stool enzyme immunoassay. Helicobacter 14:286-297.

Torres J, Camorlinga-Povce M, Perez-Perez G et al. (2001) Increasing multidrug resistance in Helicobacter pylori strains isolated from children and adults in Mexico. J Clin Microbiol 39:2677-2680.

Tutar E, Ertem D, Kotiloglu Karaa E et al. (2009) Endoscopic and histopathologic findings associated with $H$. pylori infection in very young children. Dig Dis Sci 54:111-117.

Ugras M, Pehlivanoglu E (2011) Helicobacter pylori infection and peptic ulcer in eastern Turkish children: is it more common than known? Turk J Pediatr 53:632-637.

Usta Y, Saltk-Temizel IN, Ozen H (2004) Gastric atrophy and intestinal metaplasia in Helicobacter pylori infection. J Pediatr Gastroenterol Nutr 38:548.

Vinette KM, Gibney KM, Proujansky R et al. (2004) Comparison of PCR and clinical laboratory tests for diagnosing $H$. pylori infection in pediatric patients. BMC Microbiol 4:5. 
Yucel O, Sayan A, Yildiz M (2009) The factors associated with asymptomatic carriage of Helicobacter pylori in children and their mothers living in three socio-economic settings. Jpn J Infect Dis 62:120-124.
Zeyrek D, Zeyrek F, Cakmak A et al. (2008) Association of Helicobacter pylori and giardiasis in children with recurrent abdominal pain. Turk Parazitol Derg 32:4-7.

Associate Editor: Roxane Maria Fontes Piazza

All the content of the journal, except where otherwise noted, is licensed under a Creative Commons License CC BY-NC. 